\title{
Classification of Captive North American River Otters (Lontra canadensis) Vocal Repertoires: Individual Variations, and Age Class Comparisons
}

\begin{abstract}
Carla Almonte ${ }^{1^{*}}$
${ }^{1}$ City University of New York

*Corresponding author (Email: calmonte1215@mac.com)

Citation - Almonte, C. (2014). Classification of captive North American river otters (Lontra canadensis) vocal repertoires: Individual variations, and age class comparisons. Animal Behavior and Cognition, 1(4), 502-517. doi: 10.12966/abc.11.07.2014

Abstract - This is the first study to examine in detail the vocal behaviors of North American river otters (Lontra canadensis), and the results suggest that river otters have complex vocal repertoires comprised of four distinct vocal types and seven sub-call types. The vocalizations and behaviors of ten captive North American river otter adults, one litter of newborn pups and one litter of pups at eight weeks old were recorded using a SONY Handheld DV camera and an infrared surveillance system. A quantitative analysis of 2726 calls on the adults and 299 calls for the pups was conducted for acoustic parameters that included frequencies, powers, and duration. Whine, chirp and chatter call types were the main vocal elements of the vocal repertoire and were present at birth. Pups vocals were structurally underdeveloped versions of the adult vocals and adults call types showed individual variations. This suggests that vocalizations are likely individually modified as pups enter adulthood. A unique whistle was present in newborn pup vocal repertoires but appeared to be reduced in the repertoire by eight weeks old. However, further research needs to be conducted to determine the function of the whistle.
\end{abstract}

Keywords - River Otters, Vocal repertoire, Vocalizations, Lontra canadensis, Otter pups, Communication.

North American river otters (Lontra canadensis) have relatively fluid social structures that can adapt to a wide range of ecological conditions with variable group composition (Beckel, 1991). Because the degree of sociality varies between and within habitat types, it is likely that communication in river otters is also flexible and serves several functions (Rostain, Ben-David, Groves, \& Randall, 2004). Research shows Prince William Sound nonsocial otters deposit spraints at more latrines sites than social otters, and this serves to facilitate mutual avoidance (Ben-David, Blundell, Kern, Brown, \& Jewitt, 2005). As well, documented observations suggest that during social interactions vocalizations are flexible. Wild otters produce 'screams' and 'wickers' when engaged in physical altercations (Kruuk, 2006, p. 87) and captive otters 'grunt' and 'chirp' during play (Beckel, 1991). Research implies that river otters use a variety of vocalizations to serve to maintain group cohesiveness, signal alarm or danger, to express apparent fear or anger and avoid aggressive interactions (Melquist \& Hornocker, 1983).

Vocal studies conducted on members of the subfamily Lutrinae have partially explained the vocal repertoire of the giant otter (Pteronura brasiliensis) (Bezzera, Souto, \& Schiel, 2010), sea otter (Enhydra lutris; McShane, Estes, Reidman, \& Staedler, 1995), and Eurasian otter (Lutra lutra; Gnoli \& Prigioni, 
1995) and the research suggest they have complex vocal systems. The giant otter is highly social in comparison to the sea otter and Eurasian otter that engage in limited social interactions. These studies showed that despite the differences in social behavior, similarities exist in call types exhibited and the manner in which they are used. They all exhibit a "scream," which is a high-pitched call and the Eurasian Otter and giant otter exhibit a "blow" that is described as exhalation of air.

To date, no formal studies have been conducted on river otter vocal systems, and based on the literature it is likely that the repertoire is similar to other otter species. The purpose of this study was to expand on the documented observations of river otter vocals by delineating and quantifying the vocal repertoire of captive river otter adults and pups. This was done to investigate the existence of individual variation among adults that exhibit the same call types and to compare the vocal repertories of adults and pups. In addition, the relationship between call types exhibited and the arousal state of the individual producing the call was examined. If call types are associated with particular arousal states then vocals might relay information about the temperament of an individual at a given point in time.

In nature elusive, adult river otters can be difficult to observe. As well, pups do not emerge from the natal den until approximately 6-8 weeks (Gorman, Erb, McMillan, Martin, \& Homyack, 2005), which makes it difficult to observe them during the newborn phase. The captive environment allowed for otters to be observed at any time in a $24 \mathrm{hr}$ period using non-invasive techniques. Furthermore, footage of newborn pups vocal behaviors could be captured without disturbing the birthing process or natal den. Although, captive behaviors are not a direct reflection of wild behaviors, the information gained from this study about river otter vocal behaviors could provide the groundwork for investigations of wild river otter vocal behaviors.

\section{Method}

\section{Study Sites}

The study consisted of ten adult otters, one litter of five newborn pups, and one litter of three pups at eight weeks old housed in five zoological facilities throughout the Greater New York City Area. Turtle Back Zoo located in West Orange, NJ (outdoor dimensions: 750 sq. ft; indoor dimensions: $102 \mathrm{ft}^{2}$ ) housed three adults (two female, one male). Beardsley Zoo located in Bridgeport, CT (outdoor dimensions: $900 \mathrm{ft}^{2}$; indoor dimensions: $150 \mathrm{ft}^{2}$ ) housed a male/female adult mating pair and the litter of newborn pups. Palisades Park Conservancy situated in Bear Mountain, NY (outdoor dimensions: $150 \mathrm{ft}^{2}$; indoor dimensions: $48 \mathrm{ft}^{2}$ ) housed a solitary adult male. Atlantis Aquarium located in Riverhead, NY (outdoor dimensions: $726 \mathrm{ft}^{2}$; indoor dimensions: $80 \mathrm{ft}^{2}$ ) housed a male/female adult mating pair and eight weeks old pups. Stamford Farm and Museum situated in Stamford, CT (outdoor dimensions: $2040 \mathrm{ft}^{2}$; indoor dimensions: $85 \mathrm{ft}^{2}$ ) housed a non-mating male/female adult pair.

\section{Data Acquisition}

Video and audio recordings were collected from November 2007 - November 2010. Sessions were randomly conducted during the day and overnight throughout the three years of data collection. Day sessions gave insight into how otters behaved vocally when in the presence of humans, while overnight sessions gave insight to the vocals exhibited when the otters were devoid of human presence. Day sessions occurred when the study sites were open to the public (10:00 a.m. - 4:00 p.m. ${ }^{1}$ ) and consisted of manually recording the otters for 30 consecutive minutes. A SONY DV hand-held camera and tripod were used to capture the recordings. One or two sessions were conducted per visit to a study site, and study sites were visited three times a week (Monday - Friday). The duration of the day sessions and number of visits a week to study sites were kept to a minimum to ensure the daily routines of the river otters were not disrupted. Fifteen sessions were conducted for each facility, however sessions continued if

${ }^{1}$ Hours of operation varied per study site. 
thirty usable vocals were not collected from each individual. Night sessions occurred when study sites were closed to the public (4:00 p.m. - 10:00 a.m. $\left.{ }^{2}\right)$ for 15 - 18 continuous hours (the time recordings ended were based on when the otters received their morning feedings). A temporary surveillance system was installed in the overnight sleeping quarter(s) of a given study site. It consisted of one - three infrared camera(s) (the number of cameras installed was based on the number of indoor dens at the facility), one LOUROE microphone (audio pick-up of $30 \mathrm{ft}$ diameter) and one digital video recorder (500GB). The digital video recorder was put on a timer to record for three consecutive nights and each night was one session. Nine sessions were conducted per facility, but would be increased if thirty vocals were not obtained from each otter, or to capture a birth (litters were born at Beardsley Zoo and Atlantis Aquarium). Once data collection was completed at one study site the surveillance system was uninstalled and reinstalled in the next study site.

\section{Video Analysis}

The data collection consisted of 2129 hrs of footage (day session: 55 hrs; overnight sessions: $2074 \mathrm{hrs}$ ). The footage from each session was viewed in real time to locate the times vocals were produced. All sessions that contained at least one vocal were imported into FINAL CUT PRO to edit out the video footage that contained no vocal activity leaving shorter video clips that contained only vocals. The shorter video clips were imported into RAVEN PRO 1.3 to obtain a spectrogram (Window Type: Hann: 256; $270 \mathrm{~Hz}$; overlap 50\%; discrete Fourier Transform (dft): 256) of the vocal. The spectrogram was a visual picture of the sound that was based on frequency and temporal patterns.

\section{Individual Identification \& Spectral Analysis of Vocalizations}

Spectrograms of each edited file were played back to seek out the times usable calls (isolated, void of background noise) were produced. The time a usable call was produced in the spectrogram was corresponded to the timestamp on the edited video file to make an identification of the individual producing the call. Both physical features (unique markings, fur color, tail shape, tail width and body size) and behavioral features (mouth opening; up and down movement of shoulders) were used to identify the individual producing the call. For adults when identification was not possible the call was not included in the dataset. The pups could not be individually identified because they did not have individual identities at the time sessions were conducted. The final dataset consisted of 2726 adult usable calls where the identification of the individual producing the call was known, and 299 calls from the two litters of pups, collectively. RAVEN PRO 1.3 quantitatively analyzed each call for two acoustic categories and nine acoustic parameters: Frequency (High, Low, Range, Mean, Max, and Center) and Power (Max and Average). Duration was determined by subtracting the start time from the end time. When harmonic bands were present in the spectral image, the number of bands were counted and recorded.

\section{Classification of Call Types for Adult Vocalizations}

To develop a classification system all 2726 adult and 299 pup vocals usable calls were assigned a number as well as a name based solely on the sound it produced to the human ear. Adults produced 11 distinctive sounds (call types): whine (1), chirp (2), chatter (3), creek (4), squeak (5), scream (6), grunt (7), swish (8), hiss (9), blow (10) and hiccup (11), and the pups produced four distinctive sounds: whine (1), chirp (2), chatter (3) and whistle (12). For the adults, the spectral analysis showed structural similarities in calls that were aurally different. The analysis of visual spectrograms showed that the creek, squeak, scream, hiss, swish, were structurally comparable to the whine, and the hiccup was structurally comparable to the chirp. Furthermore, the chatter spectrograms revealed it was a series of whines or

${ }^{2}$ Hours of closures varied per study site. 
chirps that occurred in rapid succession. A secondary classification system was developed considering these visual similarities. The secondary classification consisted of four fundamentally distinct call types: whine (1), chirp (2), grunt (7), and blow (10). The whine was a fundamental call type because every individual exhibited it (including pups). The chirp, grunt, and blow produced very distinct sounds and the spectral images were visually unlike the whine. Chatters were sub-divided into whine-chatter sub-types that were grouped with whines and chirp-chatter sub-types that were grouped with chirps. The creek, squeak, scream, swish, hiss, were grouped with the whine, and the hiccup was grouped with the chirp. Because whistles were unique to the pups they were not included in the discriminant function analysis.

\section{Vocal Usage and Individual Behavior}

An ethogram (Table 1) was developed using both video footage and first hand observations in order to have an inventory of all behaviors (and their definitions) that were observed. The behaviors were divided into three states of arousal and assigned a number: non-aggressive (0), moderately aggressive (1), and highly aggressive (2) (Table 1). An arousal state was defined as a particular state of mind at the time a vocalization is produced that was in regards to the individual's level of agitation. Physically expressed behaviors defined in the ethogram were used to determine an individual's arousal state and assign a code for each usable call.

\section{Inter-Observer Reliability}

To determine that the methods used to assign each usable call a name, individual, and level of arousal were repeatable a secondary observer checked for inter-observer reliability. The second observer viewed 50 video clips (10 clips from each study site) and 301 calls $(11 \%)$ of the data set. The unbiased observations of the second observer were based solely on the 11 distinct sounds, identifying techniques and behavioral definitions that were used in the methods.

\section{Statistical Analysis}

STATISTICA v7.1 was used to conduct a discriminant analysis on the adult dataset to search for statistical meaningful groups in the call classification system. If calls that sound differently are structurally distinct calls then call types should discriminate under the eleven distinctive sounds heard by ear. STATISTICA v7.1 was used to conduct a Kruskal-Wallis ANOVA to determine the presence of individual variations in adults. The ANOVA included all the variables that were determined in the quantitative analysis, but the squeak and hiccup were not included in this analysis because they were only heard from one individual. If individual variations exist, then there should be significant differences across acoustic parameters among individuals that share the same call type. The chi-square test was used to assess how the frequencies of sounds were distributed over levels of aggression. If there is an association between the arousal state of the individual and the call type that is exhibited then the calls may relay information about the temperament of the individual producing it. Morphological variations exist between adults and pups therefore to test the hypotheses that there are significant differences in frequencies, harmonics, power and duration of shared call types among age classes a Mann-Whitney Test was conducted. The Mann-Whitney Test was used because it is a non-parametric test that does not assume a normal distribution. 
Table 1

Ethogram of Captive River Otter Behaviors and Number of Individuals that Exhibited the Behavior.

\begin{tabular}{|c|c|c|c|c|}
\hline Behavior & Sub-Behavior & Definition & Arousal State Code & $\begin{array}{c}\text { Number of otters } \\
\text { that exhibited } \\
\text { behavior }\end{array}$ \\
\hline \multirow[t]{3}{*}{ Sleeping } & Indoor & $\begin{array}{l}\text { Period of rest in den for } 30 \\
\text { minutes or more }\end{array}$ & $\begin{array}{c}\text { Non-aggressive } \\
0\end{array}$ & $10 * *$ \\
\hline & Outdoor & $\begin{array}{c}\text { Period of rest for } 30 \\
\text { minutes or more; occurs } \\
\text { mainly by trees }\end{array}$ & $\begin{array}{c}\text { Non-aggressive } \\
0\end{array}$ & $10 *$ \\
\hline & Social/Group & $\begin{array}{l}\text { Sleeping with another } \\
\text { otter(s) (within an otters } \\
\text { distance away) for } 30 \\
\text { minutes or more }\end{array}$ & $\begin{array}{c}\text { Non-aggressive } \\
0\end{array}$ & $9 * *$ \\
\hline \multirow[t]{3}{*}{ Grooming } & Self & $\begin{array}{l}\text { Licking and biting of own } \\
\text { skin, fur, or paws }\end{array}$ & $\begin{array}{c}\text { Non-aggressive } \\
0\end{array}$ & 10 \\
\hline & Others & $\begin{array}{c}\text { Licking and biting of skin, } \\
\text { fur, or paws of another } \\
\text { otter }\end{array}$ & $\begin{array}{c}\text { Non-aggressive } \\
0\end{array}$ & 9 \\
\hline & Massaging & $\begin{array}{l}\text { Rubbing body or back } \\
\text { against a substrate (i.e. } \\
\text { rock, log, wall) }\end{array}$ & $\begin{array}{c}\text { Non-aggressive } \\
0\end{array}$ & 10 \\
\hline \multirow[t]{3}{*}{ Swimming } & Submerged & $\begin{array}{l}\text { Otter completely } \\
\text { submerged in water or in } \\
\text { pool and maneuvering } \\
\text { through the water for more } \\
\text { than } 30 \text { seconds }\end{array}$ & $\begin{array}{c}\text { Non-aggressive } \\
0\end{array}$ & $10 *$ \\
\hline & Acrobatic & $\begin{array}{c}\text { Underwater swimming } \\
\text { involving acrobatic } \\
\text { movements (i.e. spinning, } \\
\text { back flips) }\end{array}$ & $\begin{array}{c}\text { Non-aggressive } \\
0\end{array}$ & 9 \\
\hline & Floating & $\begin{array}{l}\text { Swimming on the back } \\
\text { during floating }\end{array}$ & $\begin{array}{c}\text { Non-aggressive } \\
0\end{array}$ & 1 \\
\hline \multirow[t]{6}{*}{ Play } & Toys & $\begin{array}{l}\text { Grasping, manipulating, or } \\
\text { playing with toys }\end{array}$ & $\begin{array}{c}\text { Non-aggressive } \\
0\end{array}$ & $10 *$ \\
\hline & Climbing & Scaling a gate or wall & $\begin{array}{c}\text { Non-aggressive } \\
0\end{array}$ & 3 \\
\hline & Plopping & $\begin{array}{l}\text { Running forward and then } \\
\text { laying body and head flat } \\
\text { and spread out onto the } \\
\text { ground }\end{array}$ & $\begin{array}{c}\text { Non-aggressive } \\
0\end{array}$ & 1 \\
\hline & Water & $\begin{array}{l}\text { Splashing water out of the } \\
\text { pool with paws }\end{array}$ & $\begin{array}{c}\text { Non-aggressive } \\
0\end{array}$ & 1 \\
\hline & Self & $\begin{array}{l}\text { Playing with body parts, } \\
\text { tail or feet }\end{array}$ & $\begin{array}{c}\text { Non-aggressive } \\
0\end{array}$ & 1 \\
\hline & Otter & $\begin{array}{l}\text { Physical contact with } \\
\text { otter(s) that are docile, and } \\
\text { playful; or more than one } \\
\text { otter manipulating a toy(s) }\end{array}$ & $\begin{array}{c}\text { Non-aggressive } \\
0\end{array}$ & $9 *$ \\
\hline Enrichment & Painting & $\begin{array}{l}\text { Painting stimulated by the } \\
\text { trainers }\end{array}$ & $\begin{array}{c}\text { Non-aggressive } \\
0\end{array}$ & 2 \\
\hline
\end{tabular}


Table 1 (cont.)

\begin{tabular}{|c|c|c|c|c|}
\hline Behavior & Sub-Behavior & Definition & Arousal State Code & $\begin{array}{c}\text { Number of otters } \\
\text { that exhibited } \\
\text { behavior }\end{array}$ \\
\hline & Training & $\begin{array}{l}\text { Other activities stimulated } \\
\text { by trainers (tricks) }\end{array}$ & $\begin{array}{c}\text { Non-aggressive } \\
0\end{array}$ & 5 \\
\hline & Seeking & $\begin{array}{l}\text { Searching behavior that } \\
\text { results from enrichment } \\
\text { (i.e. stashing food in toys) }\end{array}$ & $\begin{array}{c}\text { Non-aggressive } \\
0\end{array}$ & 2 \\
\hline \multirow[t]{3}{*}{ Aggressive } & Vocal & $\begin{array}{l}\text { Vocalizations that occur } \\
\text { within the } 2 \text { minutes } \\
\text { before, during, or } 2 \\
\text { minutes after a hostile } \\
\text { physical confrontation or } \\
\text { vocal quarrel }\end{array}$ & $\begin{array}{c}\text { Moderately Aggressive } \\
1\end{array}$ & 10 \\
\hline & Physical & $\begin{array}{l}\text { Physical attack on another } \\
\text { otter (biting, scratching), or } \\
\text { violent wrestling }\end{array}$ & $\begin{array}{c}\text { Highly Aggressive } \\
2\end{array}$ & 9 \\
\hline & Defensive/Non-physical & $\begin{array}{l}\text { Crouching head down, tail } \\
\text { positioned down }\end{array}$ & $\begin{array}{c}\text { Moderately Aggressive } \\
1\end{array}$ & 4 \\
\hline Non-aggressive & Vocal & $\begin{array}{l}\text { Vocalizations that occur } \\
\text { within the } 2 \text { minute before, } \\
\text { during, or } 2 \text { minute after a } \\
\text { non-aggressive physical } \\
\text { behavior }\end{array}$ & $\begin{array}{c}\text { Non-aggressive } \\
0\end{array}$ & 10 \\
\hline Submissive & Physical & $\begin{array}{l}\text { Subordinate behavior (i.e. } \\
\text { cowering, running away, } \\
\text { giving up after a quarrel or } \\
\text { confrontation) }\end{array}$ & $\begin{array}{c}\text { Moderately Aggressive } \\
1\end{array}$ & 5 \\
\hline \multirow[t]{4}{*}{ Stereotypical } & Scratching & $\begin{array}{l}\text { Scratching at gate or door } \\
\text { with paws repeatedly more } \\
\text { than } 5 \text { times in a row }\end{array}$ & $\begin{array}{c}\text { Moderately Aggressive } \\
1\end{array}$ & 2 \\
\hline & Pacing & $\begin{array}{l}\text { Walking back and forth } \\
\text { repeatedly in the same one } \\
\text { area }\end{array}$ & $\begin{array}{c}\text { Moderately Aggressive } \\
1\end{array}$ & 5 \\
\hline & Swimming & Swimming in circles & $\begin{array}{c}\text { Moderately Aggressive } \\
1\end{array}$ & 2 \\
\hline & Chewing & $\begin{array}{c}\text { Chewing on inanimate } \\
\text { body part }\end{array}$ & $\begin{array}{l}\text { Moderately Aggressive } \\
1\end{array}$ & 1 \\
\hline
\end{tabular}

\section{Results}

\section{Call Classification}

The results of the discriminant analysis on the classification based on sound suggested that $72 \%$ of the calls were accurately identified based on the variables that were used in this study. However, there 
was extensive overlapping in the distribution of the discriminant scores (Figure 1A). The discriminant analysis conducted on the four fundamentally distinct call classifications reached an overall accuracy of 89.1\%. The canonical discriminant functions showed distinctive groups (Whine, Chirp, Grunt, and Blow) in the distribution of the discriminant scores (Figure 1B).

A)

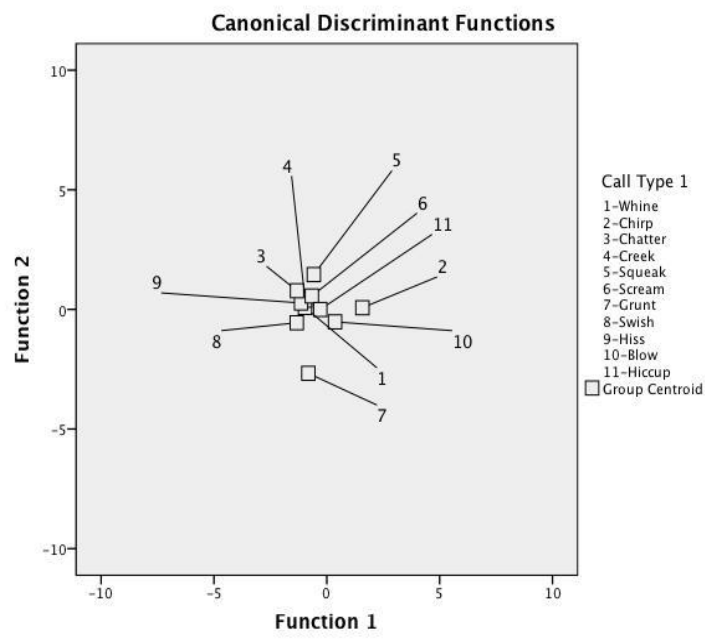

B)

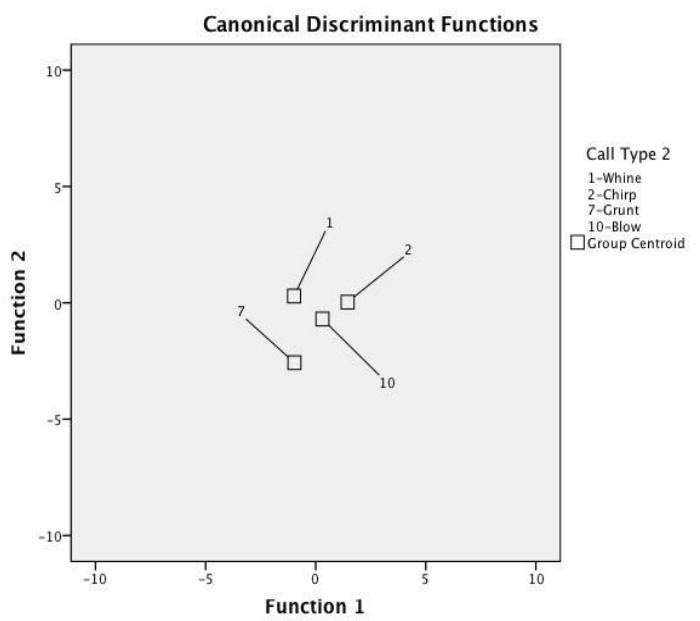

Figure 1. A) Discriminant function analysis results for the eleven sound classification systems. Each square represents a centroid for each call category and is marked with a number that represents the sound. Images were obtained using SPSS for Mac, version 20.0, SPSS Inc. B) Discriminant function analysis results for the four sound classification systems. Each square represents a centroid for each call category and is marked with a number that represents the sound. Images were obtained using SPSS for Mac, version 20.0, SPSS Inc.

\section{Fundamental Call Types}

Whine. The whine was universal to all otter's vocal repertoires. The whine call type had the greatest variation in sound. It was moderately pitched, and showed a mean duration of $1.4 \mathrm{~s}$ (Table 2). Spectrally the whine could be static or harmonic (Figure 2A, B).

Chirp. The chirp had a high frequency with a short mean duration of $0.2 \mathrm{~s}$ (Table 2), but occurred in intermittent succession. It was aurally comparable to a bird's chirp and spectrally produced a series of harmonic bands. The shape of the bands were either linear shaped or had an upside down "v" shape (Figure 2C, D).

Grunt. The grunt sounded comparable to the sound produced when a human clears their throat. It was low-pitched, with a mean duration of $0.01 \mathrm{~s}$ (Table 2). It produced a very distinct spectrogram with little variation in the images within or among the individuals that exhibited it (Figure 2E).

Blow. The blow sounds like air being blown out from the nose. Three otters exhibited this call type: two males and one female. The males produced similar spectral images, but the female produced a different spectrogram. The blow had a high frequency of $10514 \mathrm{kHz}$, and a mean duration of $0.9 \mathrm{~s}$ (Figure 2F, Table 2). 
Table 2

Descriptive Statistics for all Call Types Across the Variables (mean $\pm S D$ )

\begin{tabular}{|c|c|c|c|c|c|c|c|c|c|c|}
\hline $\begin{array}{c}\text { Call } \\
(n)\end{array}$ & $\underset{(\mathbf{k H Z})}{\mathbf{H F}}$ & $\begin{array}{c}\mathbf{L F} \\
(\mathbf{k H z})\end{array}$ & $\begin{array}{c}\mathbf{R F} \\
(\mathbf{k H Z})\end{array}$ & $\begin{array}{l}\text { MNF } \\
\text { (kHZ) }\end{array}$ & $\begin{array}{c}\text { MXF } \\
(\mathbf{k H Z})\end{array}$ & $\begin{array}{c}\mathrm{CTF} \\
(\mathbf{k H Z})\end{array}$ & $\begin{array}{c}\text { MXP } \\
\text { (dB) }\end{array}$ & $\begin{array}{l}\text { AVP } \\
\text { (dB) }\end{array}$ & $\begin{array}{c}\text { DRT } \\
\text { (s) }\end{array}$ & $\begin{array}{c}\text { HRM } \\
\text { (\#) }\end{array}$ \\
\hline $\begin{array}{l}\text { Whine } \\
\text { (959) }\end{array}$ & $5970+/-1735$ & $609+/-501$ & $5471+/-4153$ & $3289+/-922$ & $2587+/-913$ & $2573+/-817$ & $88+/-11$ & $69+/-10$ & $1.4+/-1.1$ & $1.1+/-2$ \\
\hline ADULTS & & & & & & & & & & \\
\hline $\begin{array}{l}\text { Whine } \\
\qquad(170)\end{array}$ & $4852+/-754$ & $1165+/-450$ & $3695+/-923$ & $3009+/-478$ & $1993+/-667$ & $1980+/-539$ & $70+/-4$ & $54+/-3$ & $0.5+/-0.2$ & $1.9+/-0.8$ \\
\hline PUPS & & & & & & & & & & \\
\hline $\begin{array}{l}\text { Chirp } \\
\text { (1024) }\end{array}$ & $8764+/-3395$ & $1407+/-792$ & $7480+/-4951$ & $5080+/-1752$ & $2478+/-1077$ & $2525+/-905$ & $91+/-8$ & $73+/-7$ & $0.2+/-0.4$ & $3.3+/-1.7$ \\
\hline ADULTS & & & & & & & & & & \\
\hline $\begin{array}{l}\text { Chirp } \\
\qquad(100)\end{array}$ & $4209+/-1120$ & $1890+/-684$ & $2706+/-4354$ & $3049+/-530$ & $2700+/-572$ & $2681+/-484$ & $81+/-6$ & $66+/-5$ & $0.2+/-0.1$ & $1.6+/-0.8$ \\
\hline PUPS & & & & & & & & & & \\
\hline $\begin{array}{l}\text { Grunt } \\
\text { (154) }\end{array}$ & $1996+/-3103$ & $300+/-921$ & $1697+/-2266$ & $1146+/-1990$ & $583+/-1083$ & $621+/-1151$ & $75+/-7$ & $62+/-8$ & $0.7+/-0.4$ & $0.01+/-0.16$ \\
\hline Blow & $10514+/-5296$ & $708+/-418$ & $9807+/-5331$ & $5611+/-2646$ & $1897+/-815$ & $2317+/-646$ & $86+/-8$ & $69+/-6$ & $0.3+/-0.1$ & $0.9+/-0.2$ \\
\hline $\begin{array}{l}\text { Chatter } \\
\text { (290) }\end{array}$ & $6571+/-1073$ & $661+/-472$ & $5900+/-1233$ & $3616+/-577$ & $3028+/-754$ & $3076+/-544$ & $94+/-9$ & $74+/-8$ & $1.8+/-1.3$ & $0.4+/-1.5$ \\
\hline $\begin{array}{l}\text { ADULTS } \\
\text { Chatter } \\
\end{array}$ & $5453+/-122$ & $2342+/-136$ & $2982+/-103$ & $3897+/-119$ & $3188+/-265$ & $3263+/-168$ & $58+/-1.9$ & $45+/-1.5$ & $0.6+/-0.1$ & $2.4+/-2.2$ \\
\hline PUPS & & & & & & & & & & \\
\hline $\begin{array}{l}\text { Creek } \\
\qquad(124)\end{array}$ & $6481+/-1216$ & $982+/-582$ & $5500+/-1346$ & $3669+/-823$ & $2945+/-653$ & $2896+/-527$ & $86+/-10$ & $67+/-10$ & $1.1+/-0.9$ & $0.4+/ 1.28$ \\
\hline $\begin{array}{l}\text { Squeak } \\
\text { (14) }\end{array}$ & $9644+/-2433$ & $447+/-335$ & $9197+/-2374$ & $5045+/-1268$ & $3295+/-1210$ & $3830+/-689$ & $102+/-2$ & $83+/-1$ & $2.1+/-1.5$ & $2.4+/-3.9$ \\
\hline $\begin{array}{l}\text { Scream } \\
\text { (20) }\end{array}$ & $6619+/-306$ & $449+/-388$ & $6170+/-605$ & $3534+/-175$ & $2897+/-575$ & $3000+/-304$ & $101+/-2$ & $83+/-3$ & $1.5+/-1.2$ & $0.8+/-1.5$ \\
\hline Swish & $5428+/-901$ & $881+/-300$ & $4548+/-1052$ & $3155+/-418$ & $2269+/-881$ & $2475+/-862$ & $74+/-7$ & $58+/-5.6$ & $1.4+/-1$ & $0.9+/-1$ \\
\hline Hiss (39) & $5502+/-986$ & $1713+/-576$ & $3788+/-1072$ & $3608+/-605$ & $3034+/-668$ & $3067+/-620$ & $73+/-7$ & $54+/-11$ & $1+/-0.4$ & $0.3+/-0.6$ \\
\hline Hiccup & $5698+/-774$ & $543+/-445$ & $5155+/-1092$ & $3121+/-317$ & $2344+/-1285$ & $2344+/-1151$ & $88+/-9$ & $67+/-7$ & $0.2+/-0.1$ & $1.8+/-2.1$ \\
\hline $\begin{array}{l}\text { Whistle } \\
\text { (24) }\end{array}$ & $4947+/-868$ & $998+/-274$ & $3949+/-924$ & $2973+/-448$ & $1898+/-545$ & $1789+/-354$ & $71+/-3$ & $55+/-3$ & $0.4+/-0.1$ & $2+/-1$ \\
\hline
\end{tabular}

Note Call $(n)=$ Call type and sample size $\mathrm{HF}=$ high frequency; $\mathrm{LF}=$ low frequency; $\mathrm{RF}=$ range of frequency; $\mathrm{MNF}=$ mean frequency; $\mathrm{MXF}=$ max frequency; $\mathrm{CTF}=$ center frequency; $\mathrm{MXP}=$ max power; $\mathrm{AVP}=$ average power; $\mathrm{DRT}=$ duration; $\mathrm{HRM}=$ harmonics. 


\section{Sub-Call Types}

Chatter. The chatter was aurally comparable to teeth chattering. The spectral appearance of the chatter showed it was a chirp or a whine that occurred in a rapid succession. It had a high frequency with an average duration of $1.8 \mathrm{~s}$ (Figure $2 \mathrm{G}, \mathrm{H}$ ). Chatters have been described as a staccato cry in Eurasian Otters (Gnoli \& Prigioni, 1995).

Creek. The creek was heard in five otters, and predominately females exhibited creeks. Creeks sounded like an old wooden door opening, with some slight variations based on the individual producing the call. The creek had an average power of $67 \mathrm{~dB}$, and an average duration of $1.1 \mathrm{~s}$ (Figure 2I).

Squeak. The squeak sounded like a shrieking whine with an average duration of $2.1 \mathrm{~s}$. Squeaks were spectrally graded and appeared to be a whine and a chirp used in conjunction (Figure 2J). The squeak has been described in sea otters (McShane, Estes, Riedman, \& Staedler, 1995) although, is not clear if these authors description of a squeak is analogous to the description of the chirp presented in this study.

Scream. Screams were difficult to distinguish from the whine because they looked spectrally identical and sounded very similar aurally. The main difference was the scream became increasingly louder the longer expressed. The scream was high-pitched with a mean duration of $1.5 \mathrm{~s}$ (Figure 2K, Table 2). Female sea otters have been observed screaming when separated from pups (McShane, Estes, Riedman, \& Staedler, 1995).

Hiss. The hiss sounds comparable to the hiss of a snake. The hiss is a static low frequency call (Figure 2L) that averaged $1 \mathrm{~s}$. The hiss had an average power of $54 \mathrm{~dB}$.

Swish. The swish sounded like water swirling around in a container. Its spectral image produces a static appearance (Figure 2M), and was similar to the hiss. It was a low frequency call with an average power of $58 \mathrm{~dB}$.

Hiccup. The hiccup was heard in a young female while engaged in play with a toy. It aurally sounded like a human hiccup and spectrally appeared similar to the chirp (Figure $2 \mathrm{~N}$ ).

Whistle. The whistle was unique to newborn pups, it was harmonic and appeared similar to the chirp, but has a down sweep of the harmonic bands at the start of the vocal (Figure 4G). The whistle had an average of two harmonic bands.

\section{Individual Variation}

The results of the Kruskal-Wallis ANOVA (Table 3) showed highly significant differences ( $p<$ $0.01)$ for all call types except the scream and the hiss. The hiss showed no individual variations likely because one adult female exhibited 36 of the 39 hiss vocals recorded.

\section{Vocalization Usage and Behavior}

The results of the chi-square test suggested that vocal usage was highly associated with the state of arousal $\left(X^{2}=1357, d f=20, p<0.01\right)$. The bar graph (Figure 3) showed that chirps were the dominant call type exhibited when the otter was in a non-aggressive state, and when the otter was in a highly aggressive state chatters were the dominant call types. Otters expressed various call types when exhibiting moderately aggressive behaviors. 
A)
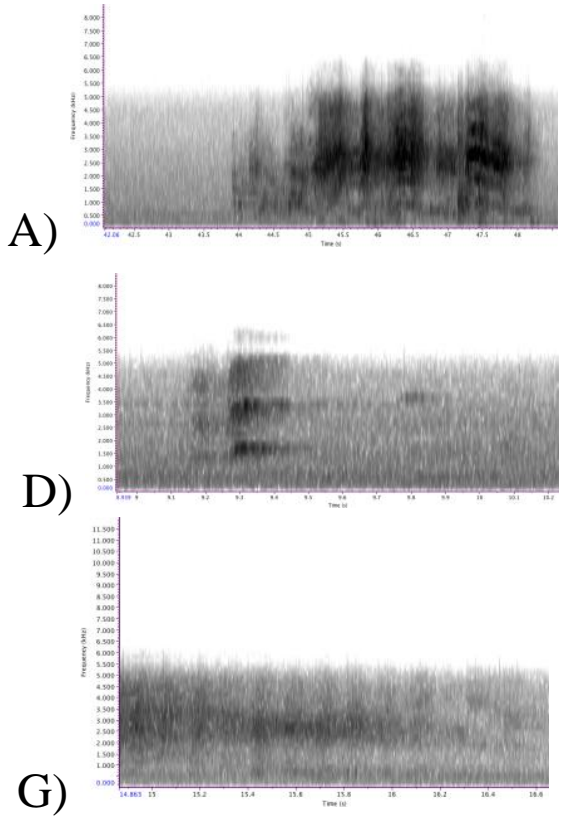

J)

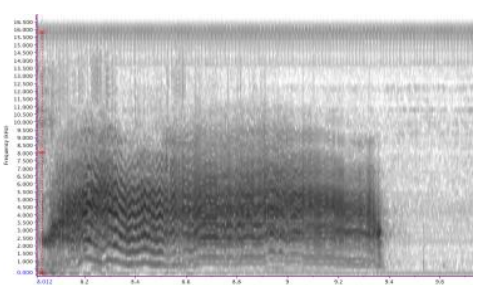

K)

E)

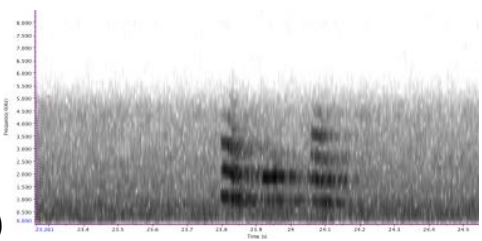

H)
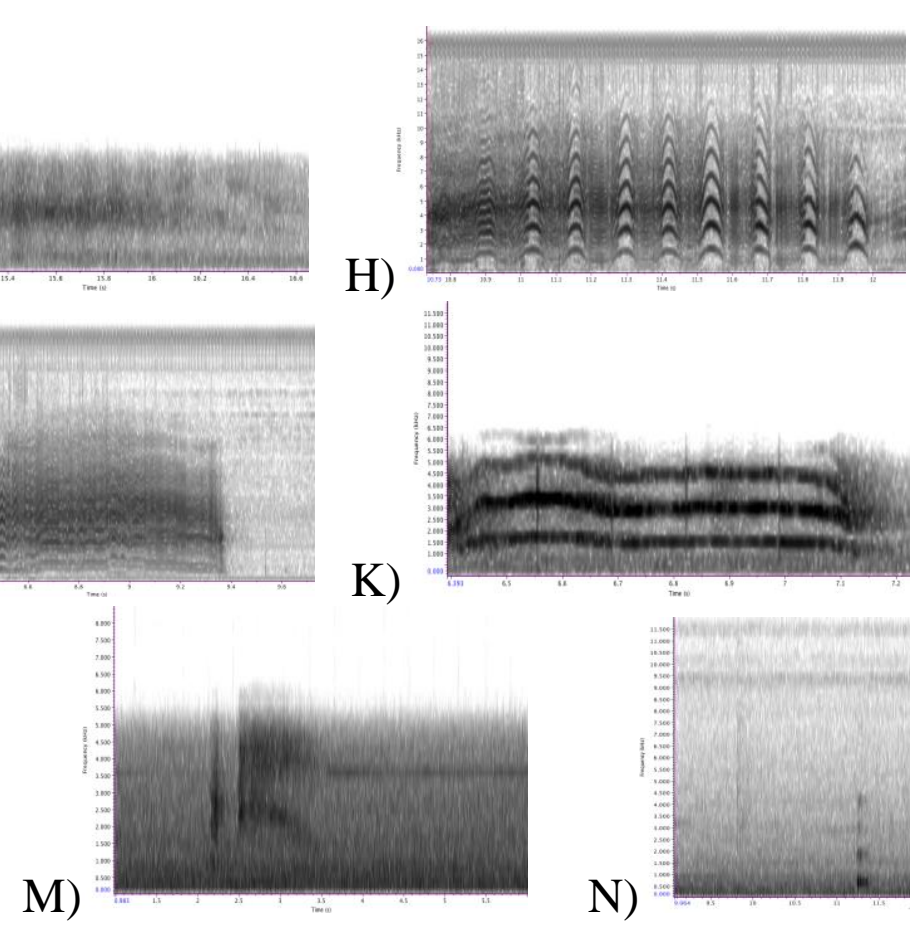
N)

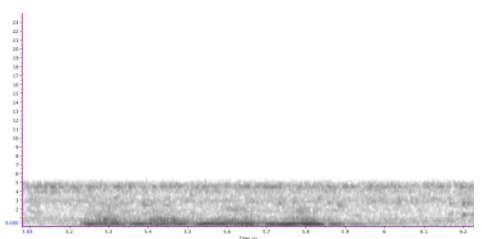

C)

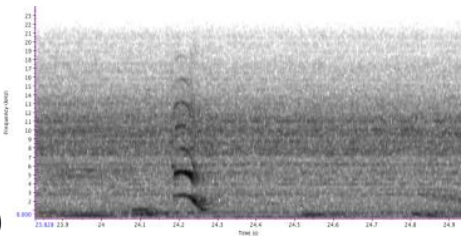

F)
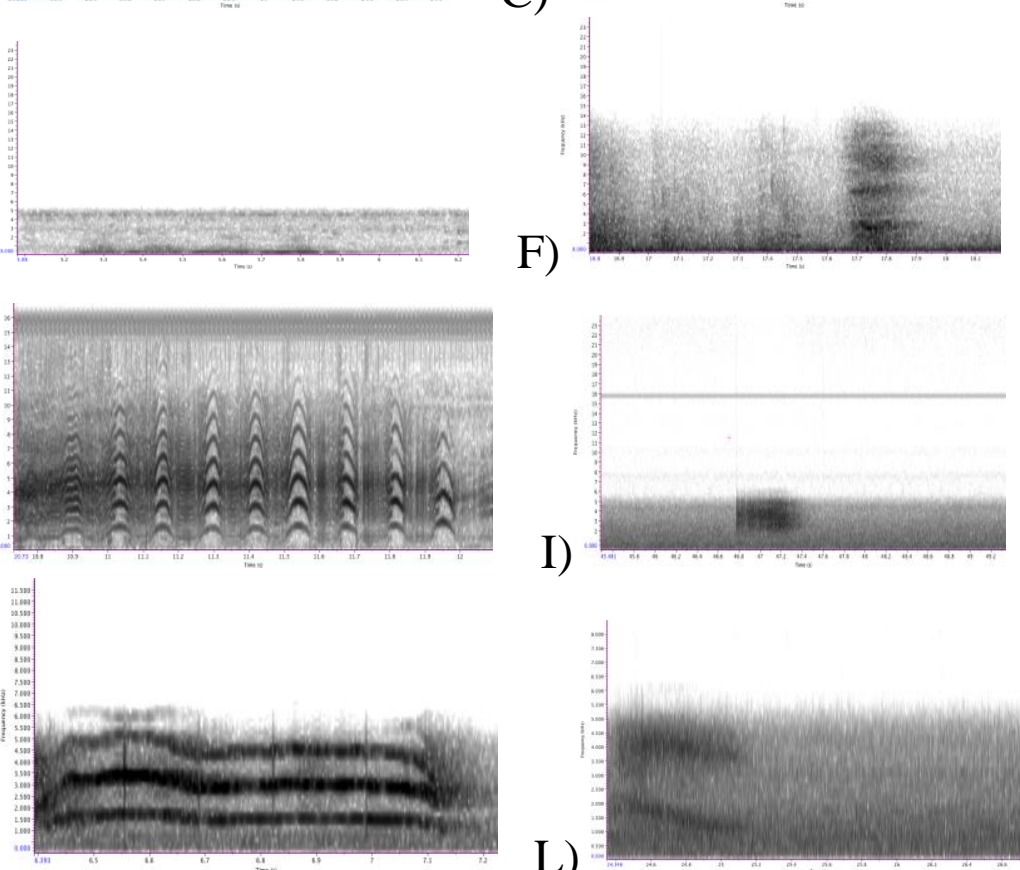

L)

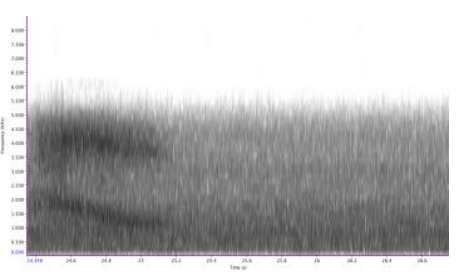

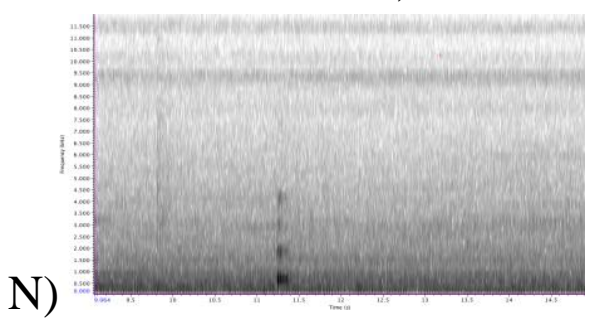

Figure 2. Spectrogram images for the call types: A) non-harmonic whine, B) harmonic whine, C) "v" shaped harmonic chirp, D) linear shaped harmonic chirp, E) grunt, F) blow, G) whine in succession chatter, H) chirp in succession chatter, I) creek, J) squeak, K) scream, L) hiss, M) swish, N) hiccup. Y-axis represents frequency (kHz) and X-axis represents time (s). 
Table 3

Results of the Kruskal-Wallis ANOVA Test for Individual Differences in Call Type.

\begin{tabular}{cllcc}
\hline Call Type & Source Of Variation & \multicolumn{1}{c}{$\boldsymbol{d f}$} & $\boldsymbol{F}$ & $\boldsymbol{p}$ value \\
\hline Whine & Between Groups & 9 & 26.28837 & $<\mathbf{0 . 0 1 *}$ \\
& Within Groups & 949 & & \\
Chirp & Between Groups & 9 & 8.83566 & $<\mathbf{0 . 0 1 *}$ \\
& Within Groups & 1017 & & \\
Grunt & Between Groups & 4 & 166.951 & $<\mathbf{0 . 0 1 *}$ \\
& Within Groups & 149 & & \\
Blow & Between Groups & 2 & 222.92068 & $<\mathbf{0 . 0 1 *}$ \\
& Within Groups & 75 & & \\
Chatter & Between Groups & 9 & 36.70185 & $<\mathbf{0 . 0 1 *}$ \\
Creek & Within Groups & 280 & & \\
& Between Groups & 4 & 7.25704 & $<\mathbf{0 . 0 1 *}$ \\
Scream & Within Groups & 119 & & \\
& Between Groups & 2 & 11.52863 & \\
Swish & Within Groups & 17 & & \\
& Between Groups & 12 & 0.31311 & $<\mathbf{0 . 0 1 *}$ \\
Hiss & Within Groups & 8 & & \\
& Between Groups & 3 & 1.06097 & \\
& Within Groups & 35 & & \\
\hline
\end{tabular}

Note. Significant differences are highlighted in bold and marked with an asterisk (*).

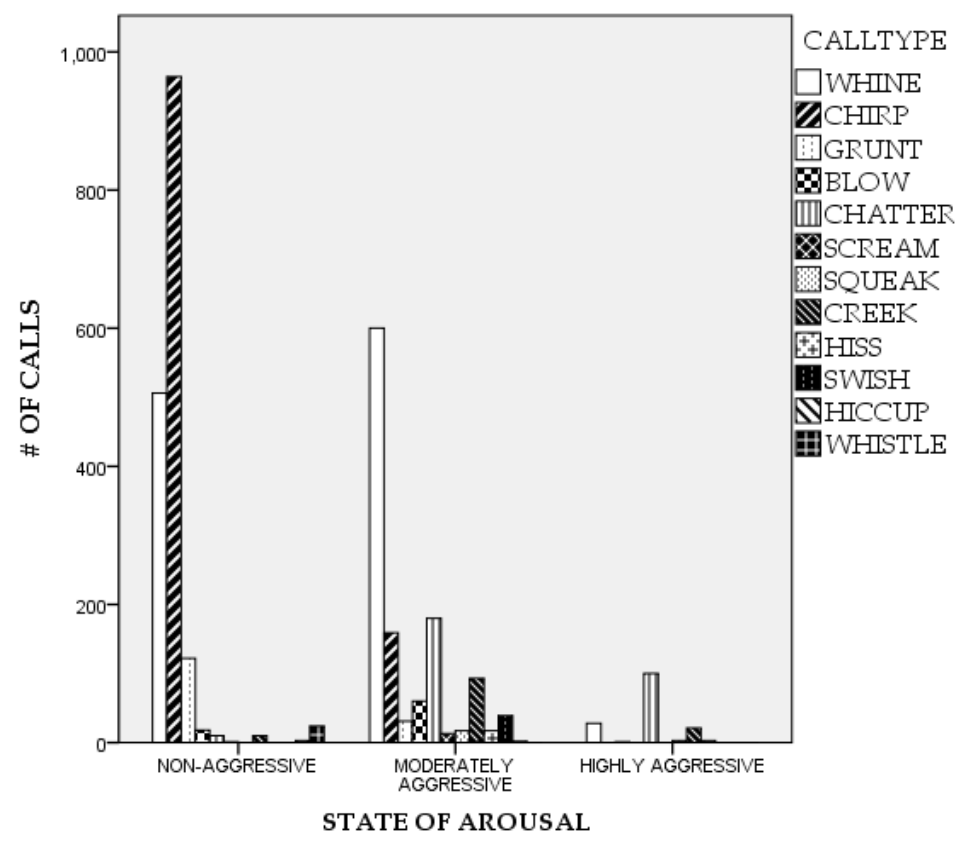

Figure 3. Bar graph representing the number of vocals heard from each call under the three states of arousal (non-aggressive; moderately aggressive; highly aggressive)

\section{Age Class Comparison}

The spectral images of the whines (Figure 4A, B) showed no distinct differences between age classes and could appear static or harmonic for both adult and pups. The Mann-Whitney results (Table 4) 
showed a significant difference in all the variables. The adults were significantly higher across variables except in the low frequency and the harmonics. The pups had a higher low frequency but a lower high frequency therefore pups had an overall lower range of frequency. The chirp's spectral images (Figure 4 D) showed that the range of frequency were different in pups and adults. As well the pups chirp produced linear harmonics, and the adults shape could either be linear or upside down "v" shaped. The Mann-Whitney showed (Table 4) significant differences across all variables. The pups had a higher low frequency and the adults had higher powers. Pups chatters are spectrally similar to the chatter-chirp spectrogram of adults because they appeared to be chirps in rapid succession (Figure 4E). The pups had a higher low frequency and the adults had higher powers and longer durations. The Mann-Whitney (Table 4) showed that adult and pup chatters were significantly different in all variables except the max and center frequency.

Table 4

Table of Hypotheses Proposed on the Variations of Adults and Pups Share Call Types

\begin{tabular}{|c|c|c|c|}
\hline Call Type & $\mathbf{H}_{\mathbf{a}}$ & $\mathbf{H}_{\mathbf{o}}$ & Mann-Whitney $p$-value \\
\hline Whine & $\begin{array}{l}\mathrm{HF}_{\mathrm{AD}} \neq \mathrm{HF}_{\mathrm{PP}} \\
\mathrm{LF}_{\mathrm{AD}} \neq \mathrm{LF}_{\mathrm{PP}} \\
\mathrm{RGF}_{\mathrm{AD}} \neq \mathrm{RGF}_{\mathrm{PP}} \\
\mathrm{MNF}_{\mathrm{AD}} \neq \mathrm{MNF}_{\mathrm{PP}} \\
\mathrm{MXF}_{\mathrm{AD}} \neq \mathrm{MXF}_{\mathrm{PP}} \\
\mathrm{CTF}_{\mathrm{AD}} \neq \mathrm{CTF}_{\mathrm{PP}} \\
\mathrm{MXPWR}_{\mathrm{AD}} \neq \mathrm{MXPWR}_{\mathrm{PP}} \\
\mathrm{AVGPWR}_{\mathrm{AD}} \neq \mathrm{AVGP} \mathrm{AR}_{\mathrm{PP}} \\
\mathrm{DRT}_{\mathrm{AD}} \neq \mathrm{DRT} \mathrm{DP}_{\mathrm{PP}} \\
\mathrm{HRM}_{\mathrm{AD}} \neq \mathrm{HRM}_{\mathrm{PP}}\end{array}$ & 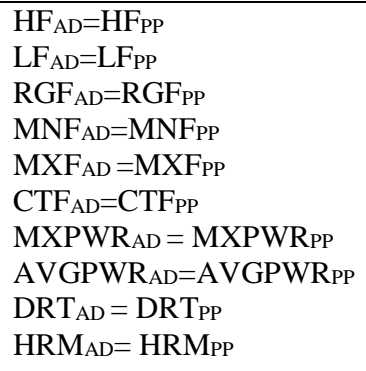 & $\begin{array}{l}<<0.01 \\
<0.01 \\
<\mathbf{0 . 0 1} \\
<0.01 \\
<0.01 \\
<\mathbf{0 . 0 1} \\
<0.01 \\
<0.01 \\
<\mathbf{0 . 0 1} \\
<\mathbf{0 . 0 1}\end{array}$ \\
\hline Chirp & $\begin{array}{l}\mathrm{HF}_{\mathrm{AD}} \neq \mathrm{HF}_{\mathrm{PP}} \\
\mathrm{LF}_{\mathrm{AD}} \neq \mathrm{LF}_{\mathrm{PP}} \\
\mathrm{RGF}_{\mathrm{AD}} \neq \mathrm{RGF}_{\mathrm{PP}} \\
\mathrm{MNF}_{\mathrm{AD}} \neq \mathrm{MNF}_{\mathrm{PP}} \\
\mathrm{MXF}_{\mathrm{AD}} \neq \mathrm{MXF}_{\mathrm{PP}} \\
\mathrm{CTF}_{\mathrm{AD}} \neq \mathrm{CTF}_{\mathrm{PP}} \\
\mathrm{MXPWR}_{\mathrm{AD}} \neq \mathrm{MXPWR}_{\mathrm{PP}} \\
\mathrm{AVGPWR}_{\mathrm{AD}} \neq \mathrm{AVGPWR} \mathrm{APP}_{\mathrm{PP}} \\
\mathrm{DRT}_{\mathrm{AD}} \neq \mathrm{DRT} \mathrm{PP}_{\mathrm{PP}} \\
\mathrm{HRM}_{\mathrm{AD}} \neq \mathrm{HRM}_{\mathrm{PP}}\end{array}$ & $\begin{array}{l}\mathrm{HF}_{\mathrm{AD}}=\mathrm{HF} F_{\mathrm{PP}} \\
\mathrm{LF}_{\mathrm{AD}}=\mathrm{LF} F_{\mathrm{PP}} \\
\mathrm{RGF}_{\mathrm{AD}}=\mathrm{RGF}_{\mathrm{PP}} \\
\mathrm{MNF}_{\mathrm{AD}}=\mathrm{MNF} \mathrm{PP}_{\mathrm{PP}} \\
\mathrm{MXF}_{\mathrm{AD}}=\mathrm{MXF} \mathrm{PPP}_{\mathrm{PP}} \\
\mathrm{CTF}_{\mathrm{AD}}=\mathrm{CTF}_{\mathrm{PP}} \\
\mathrm{MXPWR}_{\mathrm{AD}}=\mathrm{MXPWR} \\
\mathrm{AVGPWR}_{\mathrm{AD}}=\mathrm{AVGPWR} \\
\mathrm{DRT}_{\mathrm{AD}}=\mathrm{DRT} \\
\mathrm{HRM}_{\mathrm{AD}}=\mathrm{HRM}\end{array}$ & $\begin{array}{l}<0.01 \\
<0.01 \\
<0.01 \\
<0.01 \\
<0.01 \\
<0.01 \\
<0.01 \\
<0.01 \\
<0.01 \\
<0.01\end{array}$ \\
\hline Chatter & $\begin{array}{l}\mathrm{HF}_{\mathrm{AD}} \neq \mathrm{HF}_{\mathrm{PP}} \\
\mathrm{LF}_{\mathrm{AD}} \neq \mathrm{LF}_{\mathrm{PP}} \\
\mathrm{RGF}_{\mathrm{AD}} \neq \mathrm{RGF}_{\mathrm{PP}} \\
\mathrm{MNF}_{\mathrm{AD}} \neq \mathrm{MNF}_{\mathrm{PP}} \\
\mathrm{MXF}_{\mathrm{AD}} \neq \mathrm{MXF}_{\mathrm{PP}} \\
\mathrm{CTF}_{\mathrm{AD}} \neq \mathrm{CTF}_{\mathrm{PP}} \\
\mathrm{MXPWR}_{\mathrm{AD}} \neq \mathrm{MXPWR} \\
\mathrm{AVGPWR}_{\mathrm{AD}} \neq \mathrm{AVGPWR} \\
\mathrm{DRT}_{\mathrm{AD}} \neq \mathrm{DRT}_{\mathrm{PP}} \\
\mathrm{HRM}_{\mathrm{AD}} \neq \mathrm{HRM}_{\mathrm{PP}}\end{array}$ & $\begin{array}{l}\mathrm{HF}_{\mathrm{AD}}=\mathrm{HFPP} \\
\mathrm{LF}_{\mathrm{AD}}=\mathrm{LF} \\
\mathrm{RGF}_{\mathrm{AD}}=\mathrm{RGFPP} \\
\mathrm{MNF}_{\mathrm{AD}}=\mathrm{MNF} \mathrm{MPP}_{\mathrm{PP}} \\
\mathrm{MXF}_{\mathrm{AD}}=\mathrm{MXF}_{\mathrm{PP}} \\
\mathrm{CTF}_{\mathrm{AD}}=\mathrm{CTF}_{\mathrm{PP}} \\
\mathrm{MXPWR}_{\mathrm{AD}}=\mathrm{MXPWR} \mathrm{PP}_{\mathrm{PP}} \\
\mathrm{AVGPWR}_{\mathrm{AD}}=\mathrm{AVGPWR} \\
\mathrm{DRT}_{\mathrm{AD}}=\mathrm{DRT}_{\mathrm{PP}} \\
\mathrm{HRM}_{\mathrm{AD}}=\mathrm{HRM}_{\mathrm{PP}}\end{array}$ & $\begin{array}{l}<\mathbf{0 . 0 1} \\
<\mathbf{0 . 0 1} \\
<\mathbf{0 . 0 1} \\
<\mathbf{0 . 0 1} \\
>0.05 \\
>0.05 \\
<\mathbf{0 . 0 1} \\
<\mathbf{0 . 0 1} \\
<\mathbf{0 . 0 1} \\
<\mathbf{0 . 0 1}\end{array}$ \\
\hline
\end{tabular}

Note $:(\mathrm{HF}=$ high frequency; $\mathrm{LF}=$ low frequency, $\mathrm{MXF}=$ maximum frequency; $\mathrm{MXPWR}=$ maximum power; $\mathrm{DRT}=$ duration; HRM = harmonics). Hypotheses, the results of the Mann-Whitney and interpretation of results are shown. Significant $p$-values are highlighted in bold and marked with an asterisk (*). 


\section{Inter-Observer Reliability}

The inter-observer agreed with the sound identification for 270 calls (89.7\% of the data set) and disagreed for 31 calls (10.3\% of the data set). For individual identification the secondary observer agreed for 276 calls ( $91.7 \%$ of the data set) and disagreed for 24 calls (8\% of the data set) The secondary observer agreed with the arousal state identification for 274 interactions (91\% of the data set) and disagreed for 27 interactions (8.9\% of the data set) The inter-observer reliability tests results suggested that the techniques used to identify the individual, sound and arousal state were accurate and repeatable.

A)

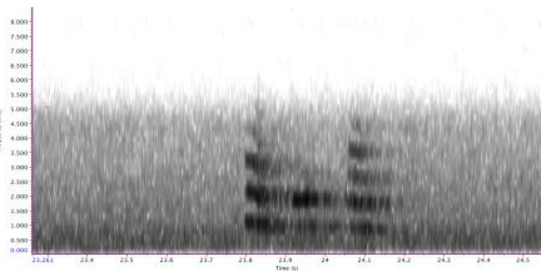

C)

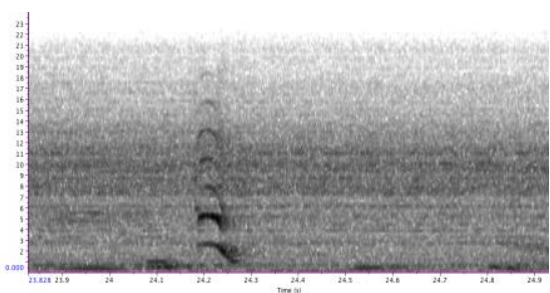

E)

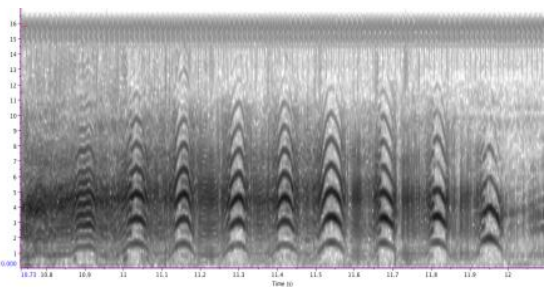

G)

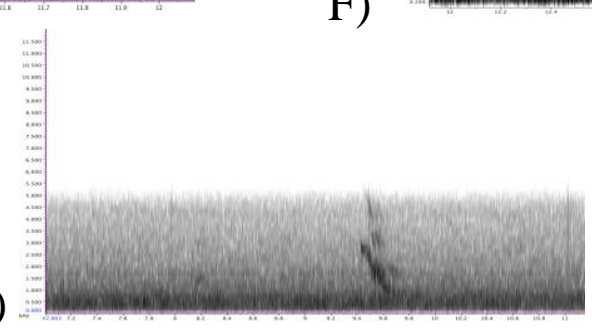

B)

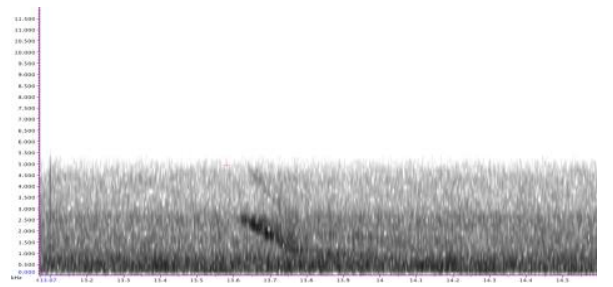

D)
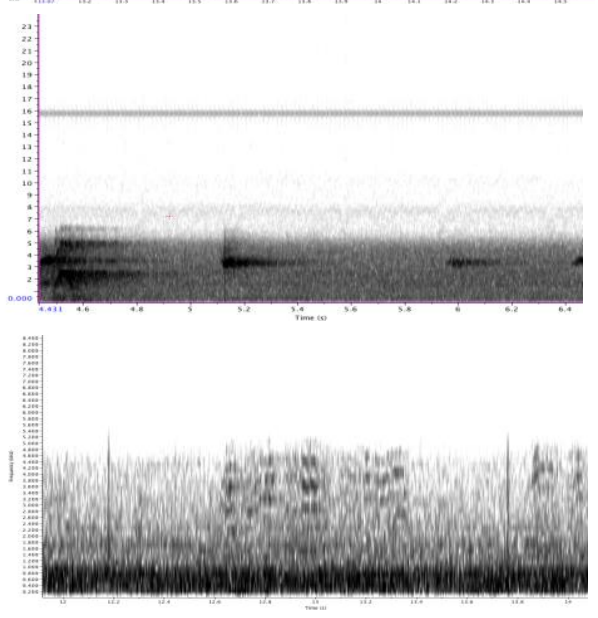

Figure 4. Spectral comparison of adults and pups shared call types: A) adult harmonic whine, B) pup whine, C) adult chirp, D) pup chirp, E) adult chatter-chirp, F) pup chatter, G) newborn pup's unique whistle

\section{Discussion}

\section{Vocal Repertoire and Call Usage of North American River Otters}

This is the first study to delineate and quantify the vocal communication system of North American river otters and the results showed that river otters have a set of complex vocals aurally similar to giant otters (Pteronura brasiliensis), sea otters (Enhydra lutris), and Eurasian otters (Lutra lutra) (Bezzera et al., 2011; Gnoli \& Prigioni, 1995; McShane et al., 1995). The vocal repertoire iss composed of several calls that have been described in other otter species (whine; chirp/squeak; blow; and scream). Like giant otters that show significant differences in their acoustic structures (Bezzera, Souto, \& Schiel, 2011), river otter call structures varied and the variations were a distinguishing factor when classifying 
calls in the repertoire. Captive river otters had four distinct call categories (whine, chirp, grunt, blow) and seven sub-type call categories (chatter, squeak, creek, scream, swish, hiss, and hiccup). Sub-type calls sounded different from the distinct calls, but were structurally similar to whines or chirps. Pup vocal repertoires consisted of whines, chirps, and chatters.

The whine was universally present in the adults and pups repertoires, and the discriminant function analysis showed that six of the sub-call type categories were structurally categorized with whines. This suggests that the whine is essential to the vocal repertoire and is the vocal that sub-call types are modified from. Furthermore, newborn pups exhibited the whine within $45 \mathrm{~s}$ of birth, implying the whine is innately present. Adults showed variations in the vocal parameters of the whine; therefore the whine might be present at birth and over time becomes individually distinct. Although, individual variations were present the whine was expressed arbitrarily and occurred when the otter was in various arousal states (Figure 3), suggesting it likely does not function to relay specific information about the state of arousal of the individual.

Newborn pups expressed the chirp at birth, and adult chirps showed individual variations. Therefore, chirps may be innately present and become individually distinct like the whine call type. Chirps were the dominant call type expressed when otters were in a non-aggressive state of arousal (Figure 3). This suggests that chirps are likely used to convey friendly messages. In addition, otters chirped during self-grooming or when massaging their body against a substrate. Thus, chirps might also be used to express feelings of contentment.

An adult female and male housed in separate facilities exhibited grunts and blows. Individual variations existed in grunts but they were spectrally and aurally similar. Morphological differences between the sexes may explain the variations, but further research is needed to confirm this. Despite the individual variations, grunts were particularly expressed when the otter was in a moderately agitated arousal state (Figure 3). Both individuals grunted when stereotypical behaviors (Table 1) were exhibited, suggesting that grunts may serve to express frustration or anxiety. The female grunted when she paced before her morning feed and the male grunted overnight while he chewed on his tail.

The blow showed individual variation, with females having higher frequencies. Like the grunt, the variations in the blow likely existed because of morphological differences between sexes. Blows were mainly exhibited when the otters were moderately agitated by a human approaching the den. Hence, the blow may be used when an otter feels endangered and serves to ward off potential threats. It has been suggested that captive Eurasian otters use their blow to ward of potential threats (Gnoli \& Prigioni, 1995).

Spectrograms revealed the chatter sound was produced when the otter whined or chirped in rapid succession rather than in isolation or intermittently. All adults exhibited chatters in their repertoires, but only the newborn pups produced chatters. Chatters were structurally like a whine or chirp and also showed individual variations. However, all adults chattered while exhibiting aggressive behaviors. During physical altercations when otters were highly aggressive chatters were the dominant call type exhibited. This suggests that chatters serves to relay antagonistic or hostile messages.

Squeaks were graded calls and were produced when the otter used the whine and chirp in conjunction. The spectral image revealed the squeak was a static whine with a harmonic chirp situated in the center of the call. Although, squeaks visually appeared to be whine and chirp call types used in conjunction, squeaks were aurally distinct from either call type. Only a solitary male otter produced squeaks particularly when a human approached the back entrance of the exhibit, and squeaks continued to be expressed for the duration of the human presence. It is possible this particular individual developed a unique call to interact with humans, and he used a squeak to fend off potential threats.

The creek, hiss, and swish vocal types were exhibited by several adult otters and were associated with moderately aggressive states of arousal (Figure 3). The eldest otter (a female) in the study predominately used these calls. The female was blind and often retreated to a corner after an altercation. In the corner she would express one or more of the calls types (creek, hiss, swish) while opening her mouth. Swish, hiss, and creek call types likely relay aggression or defensiveness.

Two separately housed pregnant females exhibited the scream. The scream did not show individual variations and both females used screams in the same manner. Approximately one month 
before the pups were born the females began to exhibit an extremely loud scream when the male was in her vicinity. Females continued to exhibit screams until pups left the natal den. Screams were produced when the male or a human approached the natal den, or when females were separated from the pups. The temporary use of screams and lack of individual variation implies that in females the scream might serve specifically to protect newborn pups. Males made several attempts to enter the den but retreated when the female screamed, suggesting this vocal was useful to deter males from approaching newborn pups. River otter newborn pups are vulnerable to infanticide (Blundell, Ben-David, \& Bowyer, 2001) and predation (Gorman et al., 2005) therefore in the wild the loud scream may function to ward off potential threats to pups from long distances.

The whistle call type was unique to newborn pups, and was expressed when the pups appeared to be locating their mother, or exploring the natal den. The natal den was probably difficult for newborn pups to maneuver through because the pups were blind at birth, and the den was dark. Therefore, it is possible that newborn pups echolocate using the whistle call type to help them navigate the natal den. Furthermore, eight weeks old pups observed after leaving the natal den did not exhibit the whistle. This implies that the whistle might be apparent in the early stages of life, but as dependency on the mother decreases the whistle is reduced and is eventually eliminated from the repertoire. However, further research is needed to confirm this.

Wild otters are adept in avoiding confrontation using scent communication (Kruuk, 2006, p. 78), and river otter spraints are used for species identification, to maintain territories, and relay social status to group members (Rostain, Ben-David, Groves, \& Randall 2004). But, the results suggest that vocal communication might also serve several functions. This study suggests that river otter vocalizations are possibly used for individual identification, to relay friendliness, aggression, frustration, or defensiveness, and to protect pups from predation. Chirps were highly associated with non-aggression and chatters were highly associated with aggression, implying that chirps and chatters vocal types are likely the most effective at expressing the temperament of an otter.

\section{Adult-Pup Vocal Comparisons}

The greatest difference between adult and pups for shared call types (whine, chirp, and chatter) lied in the range of frequencies and powers. Adult calls had greater range of frequencies because their calls contained more harmonic bands than pup vocals. As well, adult calls had a greater average power in comparison to pups. The structural differences between adult and pups suggests that whines, chirps and chatters are inherently present, underdeveloped versions of the respective adult call, and are modified as pups enter adulthood. These modifications are potentially due to changes in morphology during development, such as changes in vocal cord morphology or in body size. However, further research is needed to verify this theory.

\section{Future Research}

This study provides insight to the vocal behaviors of captive river otters, and the potential functions of call types. However, because captive behaviors are not a direct mirror of wild behaviors, it is important to investigate the vocal systems of wild otters to get a complete understanding of North American river otter vocal systems. With the groundwork established here questions can now be expanded to wild studies.

\section{Acknowledgements}

I would like to thank all the people involved with allowing me open access to the facilities for data collection: Atlantis Aquarium: Ann Yauillo (Head Curator) \& Candyce Paparo (Head Trainer), Beardsley Zoo: Don Goff (Curator), Rob Thomas (Associate Curator), Bethany Baldwin (Keeper), Chris Barker (Keeper) \& Gregg Dancho (Director), Palisades Park Conservancy/Bear Mountain Park: Edwin 
McGowan (Director) \& Melissa Gilmer (Head Trainer), Stamford Museum and Nature Center/Heckscher Farm: Lauren Satterfield (Former Director), Victoria Marr (Director) \& Mark Mogehsen (Head Keeper) and Turtle Back Zoo: Dr. Jeremy Goodman D.V.M (Director) Annemarie Ferrie (Trainer/Keeper), Gina Galanoplos \& Tamara Myhal (Trainer/Keeper). Without the support and extensive cooperation from everyone this project would not have been possible. Thank you to Lainga Tong for taking on the responsibility of secondary observer and working very hard to complete the work in a short period of time. A special thank you to my doctoral advisor/mentor Dr. Richard Veit and mentor Dr. Jennifer Basil for their valuable advice, feedback, and support. Thank you to the National Science Foundation for funding (NSF/AGEP Award HRD 0450360).

\section{References}

Beckel, A. L. (1991). Wrestling play in adult river otters (Lutra canadensis). Journal of Mammalogy, 72, 386-390.

Ben-David, M., Blundell, G. M., Kern, J. W., Maier, J. A. K., Brown, E. D., \& Jewitt, S. C. (2005). Communication in river otters: Creation of variable resource sheds for terrestrial communities. Ecology, 86, 1331-1345.

Bezzera, B. M., Souto, A. S., \& Schiel, N. (2011. Notes on vocalizations of giant otters in the flooded Igapo forests of Jau National Park, Amazonas, Brazil. Journal of Ethology, 29,169-175.

Blundell, G. M., Ben-David, M., \& Bowyer, R. T. (2001). Sociality in river otters: Cooperative foraging or reproductive strategies? Behavioral Ecology, 13, 234-141.

Gnoli, C., \& Prigioni, C. (1995). Preliminary study on the acoustic communication of captive otters (Lutra lutra). Hystrix Italian Journal of Mammalogy, 7, 289-296.

Gorman, T. A., Erb, J. D., McMillan, B. R., Martin, D. J., \& Homyack, J. A. (2005). Site characteristics of river otter (Lontra canadensis) natal dens in Minnesota. The American Midland Naturalist, 156, 109-117.

Kruuk, H. (2006). Otters: Ecology, behaviour, and conservation. Oxford University Press Inc., New York.

Melquist, W. E., \& Hornocker, M. G. (1983). Ecology of river otters in west central Idaho. Wildlife Monographs, $83,1-60$.

McShane, L. J., Estes, J. A., Riedman, M. L., \& Staedler, M. M. (1995). Repertoire, structure, and individual variation of vocalization in the sea otter. Journal of Mammalogy, 76, 414-427.

Rostain, R. R., Ben-David, M., Groves, P., \& Randall, J. A. (2004). Why do river otters scent-mark? An experimental test of several hypotheses. Animal Behaviour, 68, 703-711. 